\title{
Correction to: Application of new multi-objective optimization algorithm for EV scheduling in smart grid through the uncertainties
}

\author{
Published online: 14 March 2019 \\ ○) Springer-Verlag GmbH Germany, part of Springer Nature 2019

\section{Correction to: \\ Journal of Ambient Intelligence and Humanized \\ Computing \\ https://doi.org/10.1007/s12652-019-01233-1}

WanJun Yin ${ }^{1} \cdot$ Dinesh Mavaluru² ${ }^{2}$ Munir Ahmed ${ }^{3} \cdot$ Mazhar Abbas $^{3} \cdot$ Aida Darvishan ${ }^{4}$

In the original publication, first author WanJun Yin's affiliation was incorrectly added. The correct affiliation should read as below.

WanJun Yin.

1. Sichuan Vocational College of Information Technology, Sichuan, People's Republic of China.

Publisher's Note Springer Nature remains neutral with regard to jurisdictional claims in published maps and institutional affiliations.

The original article can be found online at https://doi.org/10.1007/ s12652-019-01233-1.

\section{Aida Darvishan}

darvishanayda@gmail.com

1 Sichuan Vocational College of Information Technology, Sichuan, People's Republic of China

2 College of Computing and Informatics, Saudi Electronic University, Riyadh, Saudi Arabia

3 Department of Management Sciences, COMSATS University Islamabad, Vehari Campus, Islamabad, Pakistan

4 Department of Industrial Engineering, University of Houston, Houston, TX, USA 